\title{
Night blindness, characteristic facies, and skeletal abnormalities in two brothers
}

\author{
ALASDAIR G. W. HUNTER, DIANE R. THOMPSON, MARTIN H. REED, \\ AND ANGELO G. MACRODIMITRIS \\ From the Departments of Pediatrics, Radiology, and Ophthalmology, Health Sciences Centre and \\ University of Manitoba, Winnipeg, Manitoba, Canada R3E $0 Z 3$
}

SUMmARY Two brothers are described with a similar physical appearance characterised by minor periorbital anomalies, malar flatness, a maxillary overbite, retrognathia, sloping shoulders, joint hyperextensibility, and minor radiological anomalies. In addition, they had a slowly progressing night blindness, myopia, and extinguished electroretinograms. The mother had mild expression of some of the physical anomalies and a decreased electroretinogram response to red light. We have been unable to find any report of similarly affected children. The possible modes of inheritance are discussed.

This paper describes two brothers with progressive night blindness and a facies characterised by downward slanting palpebral fissures, mild synophrys, epicanthus, ptosis, malar flatness, a maxillary overbite, and retrognathia. Additional findings included: gliotic fundi, myopia, sloping shoulders, joint hyperextensibility, and minor radiological abnormalities. Expression of the synrome was more severe in the elder boy and the mother showed some of the physical anomalies. Both boys had an extinguished electroretinogram, while the mother showed a diminished response to red light. X-linked recessive inheritance with partial expression in the mother, or autosomal dominant inheritance with marked variability in expression, are possible modes of inheritance.

\section{Family history}

The pedigree of the $\mathrm{H}$ family is shown in Fig. 1. The parents were unrelated and of French-Irish and Belgian origin. There was no previous family history of short stature, skeletal or visual problems.

\section{Case reports}

PATIENT II. 3

This boy weighed $4152 \mathrm{~g}$ at birth after a normal term pregnancy and delivery. Early motor milestones were slightly delayed, he did not speak any words until he

Received for publication 10 November 1978. 


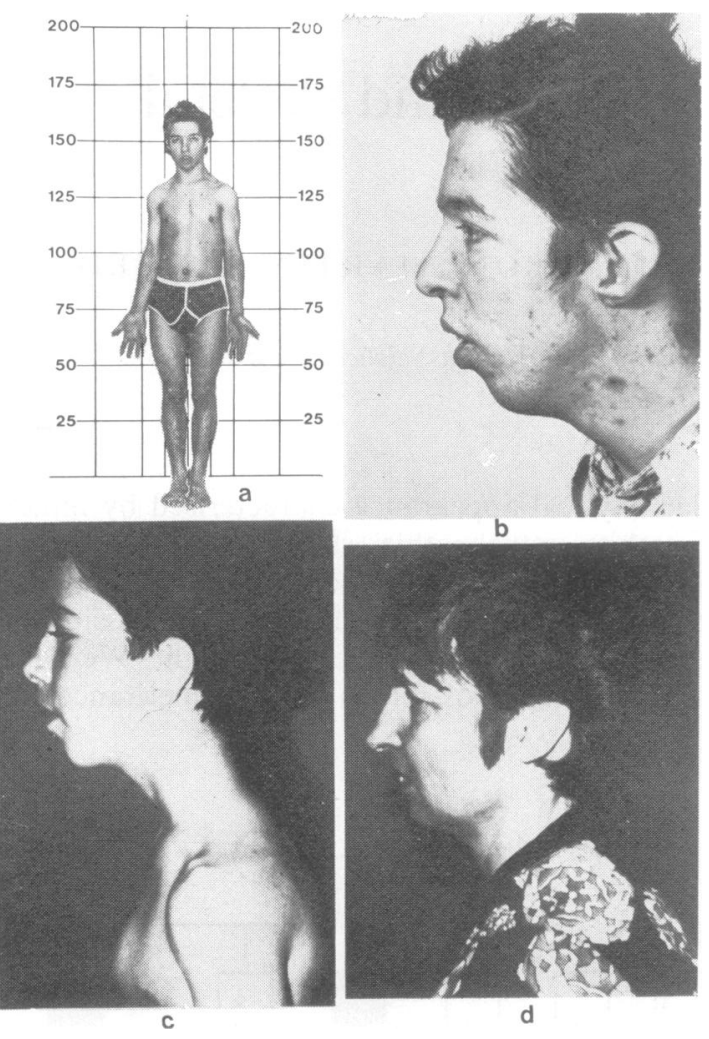

Fig. 2(a) Full frontal photograph of II.3 showing relative short stature, downward slanting palpebral fissures, small mandible, narrow sloping shoulders, and subluxated position of the left thumb. (b) Lateral view of II.3 showing maxillary overbite, marked retrognathia, and low, posteriorly rotated ears with increased space between the helix and antihelix. (c) Lateral view of II.6 showing facial resemblance to II.3 in addition to sloping shoulders and upper sternal deformity.

(d) Lateral view of mother of II.3 and II.6, showing maxillary overbite, retrognathia, and minor ear anomaly.

corrected visual acuity of 20/30 OD and 20/40 OS with mild loss of peripheral vision. The fundi showed waxy pale discs with some attenuation of the retinal vessels. A retinal hole with a floating operculum was seen superotemporally in the right eye. This was sealed after treatment with laser beam photocoagulation. There was only one clump of irregular pigmentation on the inferonasal quadrant of the left eye. There were no typical bony corpuscles in this pigment clump. Dispersed peripherally in both retinae were pale, colloidal like, yellowish, opalescent corpuscles, somewhat reminiscent of fundus albipunctatus. There was significant maxillary hypoplasia and the mandible was retrognathic (Fig $2 \mathrm{~b})$. The mouth was $4.5 \mathrm{~cm}$ wide, the palate was high and narrow, and the maxillary central incisor were very prominent. Four teeth had been removed because of extreme dental crowding with eruptio in parallel rows. Both ears measured $4 \mathrm{~cm}$ in lengt ( $<3$ rd centile), were posteriorly rotated, and inserte at a level $0.5 \mathrm{~cm}$ below a line through the inner canthi. The helix and antihelix were widely separated, with the former ceasing halfway down the eap (Fig. 2b). His neck measured $30 \mathrm{~cm}$ in circumference and sloped anteriorly. His span was $156 \mathrm{~cm}$, h upper segment/lower segment ratio 1.06 (normat chest circumference $77 \mathrm{~cm}$, and internipple distanese $20 \mathrm{~cm}$. The shoulders were narrow and drooping. $\vec{\sigma}$

All joints were hyperextensible, but this was most marked at the fingers and the first metacarpo phalangeal joint could easily be subluxated. The fingertips were bulbous. The middle finger measured $7.7 \mathrm{~cm}$ and the palm $11.3 \mathrm{~cm}$ in length; the middle phalanges of the fifth fingers were short. His kneecaps could be easily subluxated. The feet measuref $21.5 \mathrm{~cm}$ in length and there was marked bilateral pes cavus with hammer toes. Dermatoglyphs were unremarkable. His reflexes were abnormally briskẹ there was bilateral ankle clonus, a positive Hoffmann's sign, and poor fine motor co-ordinatior There was no ataxia, and no focal neurological signs were noted.

\section{LABORATORY ST UDIES}

An electroretinogram (Grass photostimulato $\overrightarrow{\vec{Q}}$ showed no evoked response (Fig. 3a). Colour vision testing with HRR plates showed achromatopsia Routine biochemical studies, including serum cholesterol and triglycerides, were normal as was $\overline{\overline{3}}$ Q-banded karyotype. An audiogram was borderline normal in high frequencies and impedence showe slightly hyperactive tympanic membranes.

$X$-rays showed the hypoplastic mandible with increased antegonal notching (Fig. 4a), abnormally shaped clavicles, a mild thoracic scoliosis, and slightly high vertebral bodies, most marked in the lumbar region. There were multiple Schmorl's nodes: (Fig. 4b), particularly in the thoracic region and tht bodies of the lumbar vertebrae had mild posteriot scalloping. The acetabular roofs were slight steeper than normal. The shafts of the long bones were constricted, so that the ends of these bones appeared prominent and there was bilater subluxation of the first metacarpal-carpal join (Fig. 4c). Metacarpal and phalangeal measurement showed the middle phalanges were all at least 3 SP below the mean, and the first and second dista phalanges were 4 and 2.5 SD below the mear? respectively (Poznanski, 1974). 

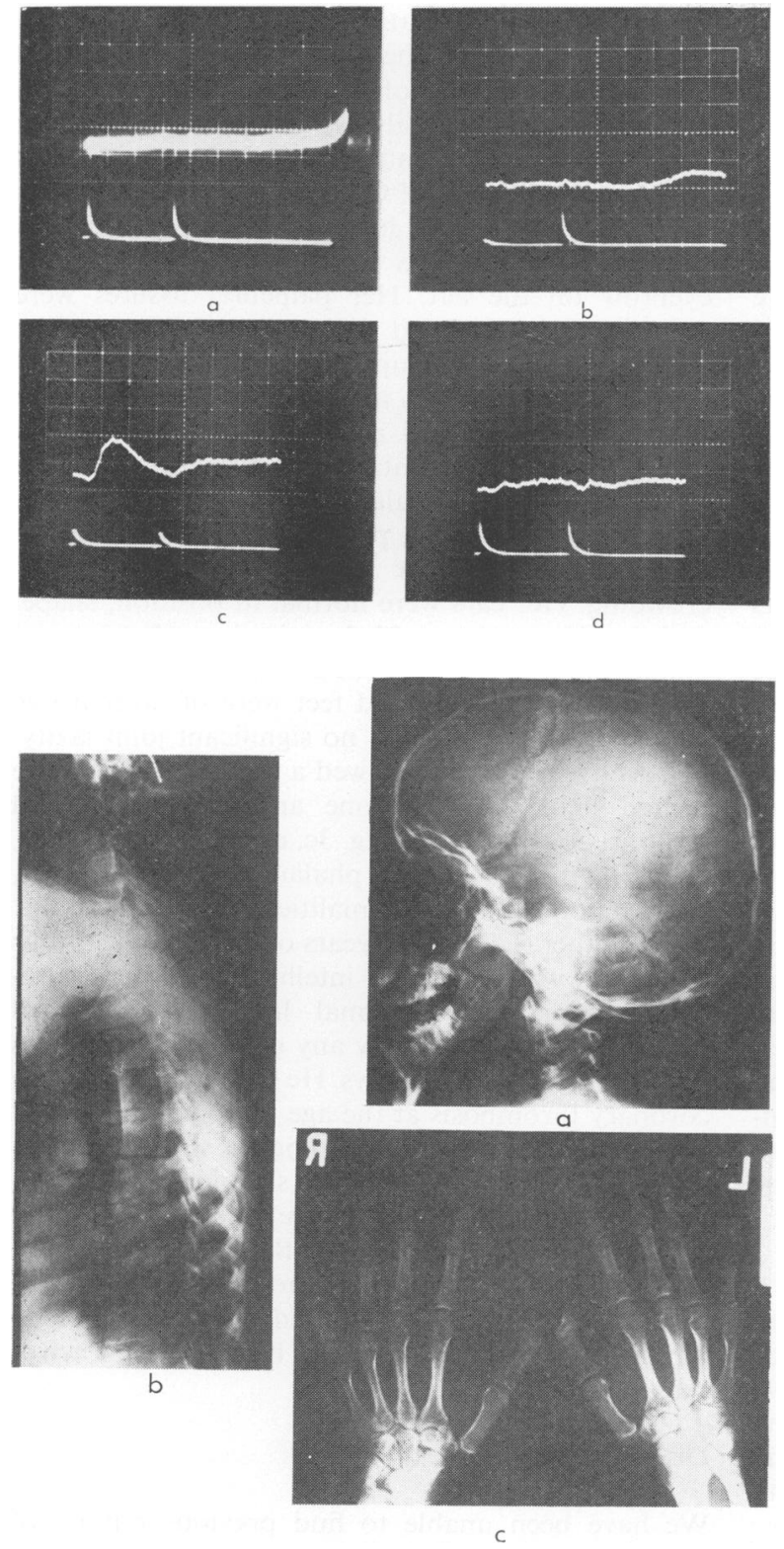

Fig. 3 Electroretinograms of II.3 (a) and II.6 (b) (intensity $\times 16)$ showing no evoked response to white light, and of the mother (c) showing normal response to white light (intensity $\times 1)$ and $(d)$ diminished response to red light (intensity $\times 16$ ).
Fig. 4 (a) Lateral view of skull of patient II.3 showing increased antigonial notch of the mandible indicating mandibular hypoplasia. (b) Lateral view of thoracic spine of II.3 showing slightly increased height of vertebral bodies and narrowing of some of the disc spaces, with Schmorl's nodes in adjacent end plates. (c) Hands of II.3 showing subluxation of the first metacarpophalangeal joints and visible hypoplasia of distal phalanges of thumbs. The middle, first, and fifth distal phalanges are short on measurement.
PATIENT II. 6.

This boy was born at term weighing $3950 \mathrm{~g}$ after an uncomplicated pregnancy and delivery. His early development and schooling have been entirely normal. At the time of examination his only complaint was that of poor physical co-ordination and diminished night vision.

At the age of 10 years, he was $138 \mathrm{~cm}$ (50th centile) tall, weighed $27 \cdot 25 \mathrm{~kg}$ ( 25 th centile), and had a head circumstance of $53.5 \mathrm{~cm}$ (50th centile). His hair was of normal texture with a single anticlockwise, right-sided, parietal whorl, a slight widow's peak, a normal posterior hairline, and mild synophrys. The palpebral fissures were horizontal and there was slight ptosis and epicanthus of the upper eyelids. The inner canthal distance was $2.9 \mathrm{~cm}$ (50th centile), the outer canthal distance $8.3 \mathrm{~cm}(<50$ th centile $)$, and both corneae were $10 \mathrm{~mm}$ in diameter (lower limit of 
normal). He was myopic and astigmatic, and had a maximally corrected visual acuity of $20 / 40$ in both eyes. The fundi were normal except, perhaps, for some pallor of the optic discs and slight narrowing of blood vessels. The nasal bridge was slightly low, the malar region was flat, and there was significant retrognathia (Fig. 2c). The mouth measured $4.6 \mathrm{~cm}$ in width, and the palate was high with prominent palatal shelves. The maxillary central incisors were protruding and there was severe dental crowding and malocclusion. Both ears had a simple, thick helix, with a large space between the helix and the prominent antihelix. The right ear was $5.5 \mathrm{~cm}$ in length (25th centile) and inserted on the inner canthal plane; the left ear measured $5.25 \mathrm{~cm}$ (15th centile) and was inserted $0.5 \mathrm{~cm}$ above the inner canthal plane ( $<10$ th centile). His neck was $27.6 \mathrm{~cm}$ in circumference and sloped anteriorly; his shoulders were narrow and sloping. His span was $131 \mathrm{~cm}$ ( $7 \cdot 7<$ height, $<3$ rd centile), his chest circumference $61 \mathrm{~cm}(<10$ th centile), and internipple distance $17 \cdot 4 \mathrm{~cm}$ (80th centile). There was marked outbowing of the upper sternum. He had a grade $2 / 6$ ejection systolic murmur over the left lower sternal border which was considered to be functional. All joints were hyperextensible, particularly the elbows, thumbs, and distal interphalangeal joints, which could be readily subluxated. There was mild clinodactyly of the fifth fingers. The middle fingers measured $6.5 \mathrm{~cm}$ (50th centile), the palms $9 \mathrm{~cm}$ (50th centile), and the feet $21 \mathrm{~cm}$ in length. The toes were bulbous with a wide space between the first and second, and the second toe appeared large and deviated medially. Reflexes were brisk and symmetrical. He showed poor co-ordination and poor fine motor movement with some mirror movements.

\section{LABORATORY STUDIES}

An electroretinogram showed almost non-existent response (Fig. 3b). Examination of visual fields was considered to be unreliable, but was probably normal. There was a mild red-green colour defect on HRR plates. Routine laboratory studies, including cholesterol, triglycerides, and an electrocardiogram, were normal.

A radiographic survey showed hypoplasia of the mandible with increased antegonial notching, fewer Schmorl's nodes than in his brother, mild hypoplasia of the iliae, and slight lateral subluxation of the first metacarpal-carpal joint. The spine, clavicle, and long bones were otherwise normal. Measurement of the metacarpal and phalangeal bones showed that the middle third and middle fourth phalanges were 3 and 4 SD below the mean, respectively. The remaining measurements were within normal limits.
OTHER FAMILY MEMBERS

The mother (I.2) of the two affected boys was 48 years old at the time of this study, was of normal intelligence, and had always enjoyed good heath. She was $155 \mathrm{~cm}$ tall, had a span of $154 \mathrm{~cm}$, weigled $57.5 \mathrm{~kg}$, and had an OFC of $55.3 \mathrm{~cm}$. Her skull wäs of normal shape, her hair of normal texture and distribution. There was a slight medial flare of her eyebrow on the left. Her palpebral fissures were downward slanting and there was a fullness of the lateral portion of the upper eyelids. Her inner antd outer canthal distances and her fundal examinategn were normal. She had a normal nasal bridge a d no significant malar flatness. Her mouth measuged $5 \mathrm{~cm}$ in width, her palate was normal, there moderate retrognathia, prominent maxillary centzal incisors with a severe outbite, and mild denferal crowding. Her ears were normal in position, shake, and size. Her neck was $33.3 \mathrm{~cm}$ in circumference and did not slope anteriorly. She had a normal chest and shoulders. Her hands and feet were of normal size and shape, and there was no significant joint laxify. An electroretinogram showed a diminished response to red light (that is, cone area), but a normal response to white light (Fig. 3c, d). A skeletal survèy, including metacarpal and phalangeal measurements, showed none of the abnormalities seen in the boys?

The father (I.1) was 49 years old at the time of this study and was of normal intelligence. All measuiements were within normal limits and physial examination did not show any of the abnormalities seen in the two affected boys. He had suffered a seve्se coronary thrombosis at the age of 47 years and häd severe limiting angina. Radiological studies did show any of the abnormalities seen in the boys and his electroretinogram was entirely normal.

The remaining three boys in the family were all: $8 \mathrm{f}$ normal intelligence and in good health. None 9 f them resembled their mother and affected brothersin physical appearance. They all had normal electioretinograms.

\section{Discussion}

We have been unable to find previous reports patients similar to the two boys in this family, who presented with nyctalopia, minor skeletal anomalißs, and an unusual facies. Their physical appearanfee probably constitutes part of the syndrome, as it was distinctive from that seen in their three other wa affected brothers, but bore some resemblance to the mother, who also had an abnormal electrojretinogram.

The mode of inheritance of this condition cann be determined with certainty from this single fami We believe that the physical resemblance of the 
mother to the two affected boys is evidence of mild expression of the syndrome, because the three unaffected boys bear no physical resemblance to her. This is supported by her diminished electroretinographic response to red light. The findings in this family are compatible with $\mathrm{X}$-linked recessive inheritance with partial expression in the female, though autosomal dominant inheritance with variable expressivity cannot be ruled out.

The electroretinographic studies in both boys were compatible with retinitis pigmentosa, and yet neither boy showed evidence of significant pigment dystrophy despite clinical symptoms of night blindness, dating back at least 13 years in the older boy. It is unusual to have this duration of symptomatic retinitis pigmentosa in the absence of significant retinal pigment (Pearlman et al., 1976). The association of myopia and choreoretinal degeneration with night blindness is well known and may occur in a sex linked recessive pattern of inheritance (François and De Rouck, 1965). Both our patients and their mother had myopia, but the significance of this association in our family is questionable, since one of the normal brothers was also myopic. Night blindness or diminished night vision may be seen as a component of a large number of syndromes including the Hallgren, Biemond, Frolich, Refsum, and A- $\beta$-lipoproteinaemia syndromes, but these can be ruled out on clinical and biochemical grounds (Geeraets, 1976).

The skeletal changes seen in our patients are relatively non-specific and do not appear characteristic of any of the established skeletal dysplasias. The elder boy had a brachydactyly which involved all the middle phalanges and the distal fifth and first phalanges. This does not exactly fit any of the defined brachydactylies, but is most like a combination of A1 and D brachydactyly (Temtamy and McKusick, 1978). An excess of type D brachydactyly has been reported among retarded patients (Villeverde and Da Silva, 1975). The brachydactyly in the younger boy was confined to the middle third and fourth phalanges. Previous reports of retinitis pigmentosa associated with skeletal abnormalities include a father and son with bony sclerosis reported by Antoine et al. (1963), and the syndrome of familial nephropathy associated with retinitis pigmentosa, cerebellar ataxia, and skeletal anomalies reported by Mainzer et al. (1970) and Popović-Rolović et al. (1976). Though there is some parallel between the phalangeal changes seen in our older patient and the latter syndrome, our patients can be clearly distinguished by the absence of ataxia or renal pathology. Schmorl's nodes, overtubulation of the long bones, and myopia are seen in Stickler's syndrome, but the other features are sufficiently distinctive to separate the two conditions (Herrmann et al., 1975).

We are grateful to Dr P. A. Adhikari who referred II. 3 to us, and to Drs John Opitz and Bonnie Grieve for their helpful suggestions. Finally, we would like to thank the $\mathrm{H}$ family for their patient co-operation, and Mrs Lilian Gordon for typing of the manuscript.

\section{References}

Antoine, B., Braun-Vallon, S., d'Anglejeau, G., Perrin, D., Dunod, J. P., and Ryckewaert, A. (1963). Nephropathie familale avec atteintes osseuse et chorio-rétinienne. Journal d'Urologie et Nephrologie, 69, 81-89.

François, J., and De Rouck, A. (1965). Sex-linked myopic chorioretinal heredo-degeneration. American Journal of Ophthalmology, 60, 670-678.

Geeraets, W. J. (1976). Ocular Syndromes. Lea and Feibiger, Philadelphia.

Herrmann, J., France, T. D., Spranger, J. W., Opitz, J. M., and Wiffler, C. (1975). The Stickler syndrome (hereditary arthrophthalmology). Birth Defects: Original Article Series, 11, No. 2, 76-103. The National Foundation-March of Dimes, New York.

Mainzer, F., Saldino, R. M., Ozonoff, M. B., and Hideyo, M. (1970). Familial nephropathy associated with retinitis pigmentosa, cerebellar ataxia and skeletal abnormalities. American Journal of Medicine, 49, 556-562.

Pearlman, J. T., Flood, T. P., and Seiff, S. R. (1976). Retinitis pigmentosa without pigment. American Journal of Ophthalmology, 81, 417-419.

Popović-Rolović, M., Čalić-Perisić, N., Bunjevacki, G., and Negovanovic, D. (1976). Juvenile nephronophthisis associated with retinal pigmentary dystrophy, cerebellar ataxia, and skeletal abnormalities. Archives of Disease in Childhood, 51, 801-803.

Poznanski, A. K. (1974). The Hand in Radiologic Diagnosis, pp. 29-44. Saunders, Philadelphia.

Temtamy, S. A., and McKusick, V. A. (1978). The genetics of hand malformations. Birth Defects: Original Article Series, 14, No. 3, 187-226. The National Foundation-March of Dimes, New York.

Villeverde, M. M., and Da Silva, J. J. (1975). Distal brachyphalangy of the thumb in mental retardation. Journal of Medical Genetics, 12, 401-404.

Requests for reprints to $\mathrm{Dr}$ Alasdair Hunter, Department of Genetics, Children's Hospital of Eastern Ontario, 401 Smyth Road, Ottawa, Ontario, Canada K1H 8L1. 